\title{
Diagnostic value of the Manning criteria in irritable bowel syndrome
}

\author{
N J Talley, S F Phillips, L J Melton, C Mulvihill, C Wiltgen, A R Zinsmeister
}

\begin{abstract}
Because unexplained 'functional symptoms' are a major cause of referral to gastroenterologists, the efficiency of the medical history to lead to a positive diagnosis of irritable bowel syndrome, without resorting to the use of expensive tests, remains a key question. Whilst the six criteria of Manning et al are widely used, data on their validity in discriminating irritable bowel syndrome from healthy controls, irritable bowel syndrome from nonulcer dyspepsia and especially among irritable bowel syndrome subgroups, are not available. To evaluate this, we studied 361 outpatients who completed a bowel disease questionnaire, which objectively measured Manning's (and other) criteria. The group included 82 patients with irritable bowel syndrome, 33 with non-ulcer dyspepsia, 101 with organic gastrointestinal disease, and 145 healthy controls. Diagnoses were based on a full and independent clinical evaluation, not on responses to the bowel disease questionnaire. Reliability was assessed by a test-retest procedure. All six of the individual Manning criteria were found to be reliable (median kappa $=0.79$ ). Based on a logistic regression analysis of the discriminatory value of Manning's criteria, as the number of positive criteria increased, so did the predicted probability of irritable bowel syndrome. This predictive value was highest in younger patients and in females. The Manning criteria discriminated irritable bowel syndrome from organic gastrointestinal disease and from all nonirritable bowel syndrome gastrointestinal disease with a sensitivity of $58 \%$ and $42 \%$, and a specificity of $74 \%$ and $85 \%$, respectively. Stools that were often loose and watery provided an additional independent criterion for distinguishing irritable bowel syndrome from non-irritable bowel syndrome. Thus, symptoms can be used to diagnose irritable bowel syndrome positively, but Manning's criteria are not highly sensitive.
\end{abstract}

Irritable bowel syndrome is the most common disorder encountered by gastroenterologists,' yet its diagnosis by simple means remains a dilemma. Indeed, identification by exclusion is still widely utilised in clinical practice. ${ }^{23}$ In an attempt to be more precise, Manning and his coworkers reported the prevalence of 15 symptoms in irritable bowel syndrome and compared these with symptoms in patients with organic disease. They concluded that six cardinal symptoms discriminated the painful variant of irritable bowel syndrome (spastic colon) from organic bowel disease. ${ }^{2}$ The key symptoms were (i) visible abdominal distension, (ii) pain relieved by a bowel action, (iii) more frequent stools with the onset of pain, (iv) looser stools with the onset of pain, (v) rectal passage of mucus, and (vi) a sensation of incomplete evacuation. The more of these symptoms that were present, the more likely it was that patients had irritable bowel syndrome. Subsequently, it has been proposed that the spastic colon could be defined by the presence of abdominal pain and any three of these six symptoms.

This empirical approach has been used commonly in clinical research ${ }^{+7}$ and has been recommended as standard practice, ${ }^{8}$ yet there are few data to confirm the validity of the Manning criteria. $^{910}$ Thompson reported in 1984 that, although the Manning criteria discriminated irritable bowel syndrome from peptic ulcer disease, they did less well in discriminating irritable bowel syndrome from inflammatory bowel disease. ${ }^{9}$ The value of these symptoms has not been assessed in patients with non-ulcer dyspepsia or in an apparently healthy population. Kruis et al developed a different system of scoring to distinguish irritable bowel syndrome from organic bowel disease, " but this has not been widely adopted.

The purpose of the present study was to evaluate the reliability and discriminatory value of the Manning criteria in irritable bowel syndrome. In particular, we wanted to determine if we could separate irritable bowel syndrome, or its subgroups, from healthy controls, from patients with non-ulcer dyspepsia or from those with organic gastrointestinal disease, using an objective self-report questionnaire. We also wished to determine if other symptoms would provide additional discriminatory value.

\section{Methods}

\section{PATIENTS}

We studied 395 consecutive patients who presented to the outpatient clinics of Mayo Clinic in 1987-1988 for management of gastrointestinal complaints (Division of Gastroenterology) or for a routine physical examination (Division of Preventive Medicine). Of this total, 361 (91\%) consented to participate; they completed a bowel disease questionnaire before their diagnostic evaluations. The final diagnosis for each patient was based on an independent clinical evaluation, supplemented by the results of investigations, all being assessed by experienced staff physicians of Mayo Clinic. Responses to the questionnaire were not shown to the examining physicians and were not used to arrive at the final diagnosis.

Of the subjects completing the questionnaire, 115 were diagnosed ultimately as having 
TABLE I Patients completing the bowel disease questionnaire $^{\star}$

\begin{tabular}{llll}
\hline $\begin{array}{l}\text { Patients } \\
(n)\end{array}$ & Final diagnosis & $\begin{array}{l}\text { Mean age } \\
\text { (years) }\end{array}$ & Men:women \\
\hline 82 & Irritable bowel syndrome & 50 & $28: 54$ \\
33 & Non-ulcer dyspepia & 51 & $13: 20$ \\
101 & Organic gastrointestinal disease & 57 & $54: 47$ \\
145 & Healthy controls & 49 & $86: 59$ \\
\hline
\end{tabular}

$\star 361 / 395$ completed the questionnaire.

functional gastrointestinal disease; 82 had the irritable bowel syndrome, defined as abdominal pain and an abnormal bowel habit in the absence of organic disease, and 33 were categorized as non-ulcer dyspepsia. All were fully evaluated by a consultant gastroenterologist; all had undergone extensive diagnostic testing, including endoscopy and barium studies, to rule out organic disease. One hundred and one patients were diagnosed as having organic gastrointestinal disease; 37 had gastroesophageal reflux, 28 peptic ulceration, four colonic cancer, six inflammatory bowel disease, and the rest had miscellaneous gastrointestinal diseases. One hundred and forty five healthy subjects were attending for routine physical examinations and were not diagnosed as having gastrointestinal or other serious organic disease; any subject in whom a diagnosis of irritable bowel syndrome, non-ulcer dyspepsia, or other gastrointestinal diseases was made was removed from the control group (Table I).

\section{PATIENTS WITH FUNCTIONAL BOWEL}

DISEASE

The patients labelled as irritable bowel syndrome were subdivided into the following two groups: (1) Pain predominant irritable bowel syndrome defined as more than six episodes of abdominal pain in the last year $(n=66)$. Of these, $24 \%$ had constipation (defined as less than three stools per week or stools that were hard and difficult to evacuate more than $25 \%$ of the time), $41 \%$ had diarrhoea (defined as more than three stools per day or, loose, watery stools more than $25 \%$ of the time), $8 \%$ had alternating constipation and diarrhoea, and $27 \%$ had pain but did not fit into our strict definitions of constipation or diarrhoea. ${ }^{7}$ (2) Irritable bowel syndrome with fewer than six episodes of pain in the last year $(n=16)$; of these, $25 \%$ had constipation, $56 \%$ had diarrhoea, and $19 \%$ did not fit into either of these categories.

The 33 patients categorised as having nonulcer dyspepsia were diagnosed on the basis of chronic or recurrent upper abdominal symptoms (pain or discomfort, or nausea) associated with normal endoscopic findings in the oesophagus, stomach, and duodenum.' Any patient with non-ulcer dyspepsia who was also diagnosed as having irritable bowel syndrome or organic gastrointestinal disease was excluded from this group.

\section{ASSESSMENT OF SYMPTOMS}

All 361 subjects completed the bowel disease questionnaire before diagnostic evaluation. This instrument is a self-report measure of abdominal pain and bowel habit; it includes the six criteria of Manning et al.: The bowel disease questionnaire has been reported elsewhere to be reliable (median kappa 0.78 , range $0.52-1.0$ for gastrointestinal symptom items) with a high degree of criterion related and construct validity. ${ }^{13}$

To determine the reliability of the Manning criteria, 42 subjects selected from all groups underwent a test-retest study 24 hours to seven weeks after the initial questionnaire.

STATISTICAL ANALYSIS

A one-way non-parametric analysis (KruskalWallis test) was used to compare the distribution of the Manning criteria score (defined as the number of criteria present) among the groups, and Wilcoxon's rank-sum test was used for pairwise comparisons of this distribution between irritable bowel syndrome subgroups. Logistic regression analysis evaluated the ability of the Manning criteria score to discriminate all irritable bowel syndrome and pain predominant irritable bowel syndrome patients from (i) healthy subjects, (ii) organic gastrointestinal disease, (iii) all non-irritable bowel syndrome patients, and (iv) non-ulcer dyspepsia patients. In these analyses, adjustments for age and sex were made by including these variables in the logistic regression model. An analysis was undertaken in the irritable bowel syndrome patient subgroups to determine whether the Manning criteria score identified pain predominant irritable bowel syndrome $v$ irritable bowel syndrome with six or less pain episodes in a year; a similar analysis was used to determine if the Manning score identified constipated irritable bowel syndrome $v$ diarrhoeal irritable bowel syndrome in each of the subgroups.

Separate logistic regression analyses determined whether 14 additional variables - namely, upper abdominal pain; lower abdominal pain; night pain waking the subject from sleep; pain aggravated by food; $<3$ stools per week; $>3$ stools per day; stools that were often $[>25 \%$ of

TABLE II Prevalence (\%) of the Manning criteria in the irritable bowel syndrome and other clinical groups

\begin{tabular}{|c|c|c|c|c|c|}
\hline \multirow[b]{2}{*}{ Criteria of Manning et al } & \multicolumn{5}{|c|}{ Clinical subgroups } \\
\hline & $\begin{array}{l}\text { IBS with pain } \\
>6 \text { times/vear } \\
(n=66)\end{array}$ & $\begin{array}{l}\text { IBS with pain } \\
=6 \text { times/year } \\
(n=16)\end{array}$ & $\begin{array}{l}\text { Non-ulcer } \\
\text { dyspepsia } \\
(n=33)\end{array}$ & $\begin{array}{l}\text { Organic } \\
\text { gastrointestinal } \\
\text { disease }(n=101)\end{array}$ & $\begin{array}{l}\text { Healthy } \\
\text { controls } \\
(n=145)\end{array}$ \\
\hline 1 Visible abdominal distension & 44 & 38 & 36 & 23 & 7 \\
\hline 2 Pain relief with defecation, often & 50 & 13 & 33 & 33 & 19 \\
\hline 3 More frequent stools at pain onset, often & 46 & 6 & 9 & 13 & 8 \\
\hline 4 Looser stools at pain onset, often & 47 & 13 & 21 & 20 & 8 \\
\hline 5 Mucus per rectum & 50 & 44 & 42 & 20 & 9 \\
\hline 6 Feeling of incomplete evacuation, often & 58 & 50 & 48 & 32 & 16 \\
\hline
\end{tabular}


TABLE III Prevalence of combinations of the Manning criteria in the irritable bowel syndrome and other groups

\begin{tabular}{llll}
\hline & \multicolumn{3}{l}{ Number of criteria } \\
\cline { 2 - 4 } Patient group & $\begin{array}{l}\text { \% with }>1 \\
\text { symptoms }\end{array}$ & $\begin{array}{l}\text { \% with } \geq 3 \\
\text { symptoms }\end{array}$ & $\begin{array}{l}\text { \% with all } \\
6 \text { symptoms }\end{array}$ \\
\hline All IBS $(\mathrm{n}=82)$ & 93 & 53 & 6 \\
IBS with pain $>6$ episodes/year $(\mathrm{n}=66)$ & 92 & 61 & 8 \\
IBS with pain $\leq 6$ episodes/year $(\mathrm{n}=16)$ & 94 & 19 & 0 \\
Non-ulcer dyspepsia $(\mathrm{n}=33)$ & 88 & 27 & 0 \\
Organic disease $(\mathrm{n}=101)$ & 58 & 26 & 0 \\
Healthy controls $(\mathrm{n}=145)$ & 37 & 7 & 0 \\
\hline
\end{tabular}

the time] loose and watery; hard stools often; strains often; laxative use; blood in stools; recent change in bowel habit; abnormal bowel habit; and weight change, provided significant additional, independent discriminatory information over and above age, sex, and the Manning score. The sensitivity and specificity of the various logistic models were also estimated. The estimated probabilities of irritable bowel syndrome as a function of the variables age, sex, and Manning score were computed for several models using the estimated coefficients from the logistic regression analyses.

The kappa statistic ${ }^{14}$ was used to assess agreement in responses for patients with test-retest data. The reliability of responses to the six Manning criteria was based on $95 \%$ confidence intervals for estimates of the kappa statistics. A kappa statistic value of 0 implies an agreement no different from chance alone, and thus a $95 \% \mathrm{CI}$ which does not contain zero corresponds to significant agreement between test and retest responses. A kappa estimate of 1.0 implies perfect agreement.

\section{Results}

The prevalence of the Manning criteria in all patients is summarised in Tables II and III. There was a significant difference in the Manning criteria score between the irritable bowel syndrome subgroup in whom pain predominated; $61 \%$ of this group had three or more criteria present, compared with the remaining irritable bowel syndrome patients of whom $19 \%$ had three or more criteria $(p=0.002)$. Differences in the Manning criteria score between those irritable bowel syndrome patients with constipation and those with diarrhoea were not detected among the irritable bowel syndrome subgroups. Healthy controls, patients with nonulcer dyspepsia and those with organic disease had significantly lower scores for the Manning criteria than did irritable bowel syndrome patients (all $\mathrm{p}<0 \cdot 001$ ).

The sensitivity and specificity of the Manning criteria were calculated by logistic regression models using a score based on the six criteria of Manning $e t$ al in addition to age and sex. When all irritable bowel syndrome patients were compared with healthy subjects, the sensitivity of the Manning criteria was $65 \%$ and the specificity was $86 \%$. When all irritable bowel syndrome patients were compared with organic gastrointestinal disease, the sensitivity and specificity of the score were $58 \%$ and $74 \%$, respectively. In contrast, when all irritable bowel syndrome patients were compared with all other diseased subjects, the sensitivity fell to $42 \%$, although the specificity was $85 \%$. The Manning criteria were highly sensitive $(97 \%)$ in discriminating all irritable bowel syndrome from non-ulcer dyspepsia, but were not specific $(3 \%)$.

When the pain predominant irritable bowel syndrome subgroup was compared with healthy subjects and organic gastrointestinal disease patients, the sensitivities of the Manning score were $70 \%$ and $56 \%$, and the specificities were $90 \%$ and $77 \%$, respectively.

The logistic regression models were used to calculate the estimated probability of irritable bowel syndrome using the Manning criteria score in addition to age and sex (Table IV). The predictive probability of the Manning criteria for irritable bowel syndrome increased with the number of criteria present - that is, with higher scores, the probability for irritable bowel syn-

TABLE IV Predicted percentage probability of the irritable bowel syndrome as function of age, sex, and number of Manning criteria present

\begin{tabular}{lllll}
\hline & & \multicolumn{3}{l}{$\begin{array}{l}\text { Predicted probability of } I B S^{\star} \mathrm{v} \\
\text { those without }\end{array}$} \\
\cline { 2 - 5 } $\begin{array}{l}\text { Number of Manning } \\
\text { criteria (1-6) }\end{array}$ & $\begin{array}{l}\text { At age } \\
\text { 20 years }\end{array}$ & $\begin{array}{l}\text { At age } \\
\text { 40 years }\end{array}$ & $\begin{array}{l}\text { At age } \\
60 \text { years }\end{array}$ \\
\hline Men & Any 2 & 51 & 38 & 26 \\
& Any 4 & 72 & 61 & 48 \\
Women & All 6 & 87 & 80 & 70 \\
& Any 2 & 64 & 51 & 38 \\
& Any 4 & 82 & 73 & 61 \\
& All 6 & 92 & 87 & 80 \\
\end{tabular}

^Includes all subgroups of irritable bowel syndrome

TABLE V Prevalence (\%) of additional symptoms to those of Manning et al

\begin{tabular}{|c|c|c|c|c|c|}
\hline \multirow[b]{2}{*}{ Symptoms } & \multicolumn{5}{|c|}{ Diagnostic group } \\
\hline & $\begin{array}{l}\text { IBS and pain } \\
>6 \text { times/year } \\
(n=66)\end{array}$ & $\begin{array}{l}\text { IBS and pain } \\
\leq 6 \text { times/year } \\
(n=16)\end{array}$ & $\begin{array}{l}\text { Non-ulcer } \\
\text { dyspepsia } \\
(n=33)\end{array}$ & $\begin{array}{l}\text { Organic } \\
\text { gastrointestinal } \\
\text { disease }(n=101)\end{array}$ & $\begin{array}{l}\text { Healthy } \\
\text { controls } \\
(n=145)\end{array}$ \\
\hline 1 Upper abdominal pain $>6$ times in last year & 56 & 0 & 94 & 43 & 3 \\
\hline 2 Lower abdominal pain $>6$ times in last year & 58 & 0 & 18 & 24 & 6 \\
\hline 3 Night pain - that is, wakes from sleep & 64 & 25 & 76 & 44 & 4 \\
\hline 4 Pain aggravated by food & 35 & 0 & 45 & 22 & 3 \\
\hline $5<3$ bowel movements/week & 23 & 6 & 15 & 6 & 6 \\
\hline $6>3$ bowel movements/day & 34 & 25 & 21 & 15 & 7 \\
\hline 7 Stools oftent loose and watery & 56 & 63 & 15 & 28 & 14 \\
\hline 8 Stools often hard & 45 & 40 & 45 & 39 & 17 \\
\hline 9 Strains often & 42 & 44 & 52 & 33 & 15 \\
\hline 10 Laxative use & 47 & 31 & 33 & 39 & 19 \\
\hline 11 Blood in stools & 24 & 31 & 21 & 19 & 12 \\
\hline 12 Recent change in bowel habit in the last year & 41 & 50 & 27 & 22 & 8 \\
\hline 13 Bowel habit reported to be abnormal in the last & t 68 & 56 & 36 & 44 & 13 \\
\hline 14 Weight loss & $\begin{array}{l}08 \\
17\end{array}$ & $\begin{array}{l}50 \\
19\end{array}$ & 15 & 11 & 1 \\
\hline
\end{tabular}

tOften $=>25 \%$ of the time. 


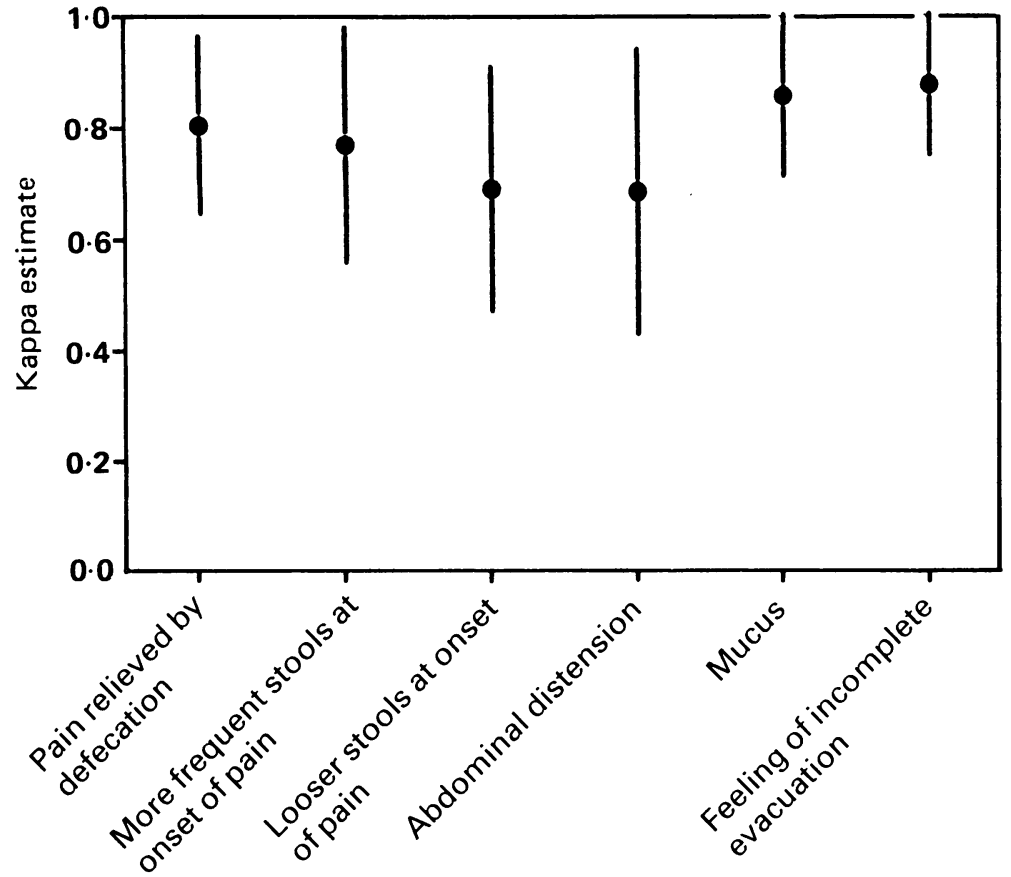

Manning et al criteria

Figure I: Kappa statistics for each question in Manning criteria with 95\% confidence interval 1st test $\mathrm{v} 2$ nd test $(n=42)$. estimated the statistical significance of the findings, the report generated important hypotheses.

The present study prospectively and objectively evaluated the Manning criteria not only for the diagnosis of irritable bowel syndrome but also for several subgroups of irritable bowel syndrome. Of particular note, we were able to use a questionnaire that has been validated. Our results suggest that the Manning criteria can discriminate all forms of irritable bowel syndrome from healthy controls and from patients with organic gastrointestinal disease. Indeed, two criteria (mucus and incomplete evacuation) that were not quite statistically significant in the original study: were found to be significant discriminators in the present investigation. We also found that the more Manning criteria reported, the greater the probability of irritable bowel syndrome; this confirms the findings of Thompson." The Manning criteria were not particularly useful in distinguishing irritable bowel syndrome from non-ulcer dyspepsia. The addition of one other criteria, however, specifically the symptom of 'stools that were loose and watery more than $25 \%$ of the time', improved the predictive value of the Manning criteria. None of the other responses improved the Manning criteria significantly.

Certain limitations of the present study need to be recognised. The group of patients with organic gastrointestinal disease was heterogeneous, and further studies with a more homogeneous group of 'disease controls' are needed. It is also possible that there were undetected irritable bowel syndrome sufferers in the healthy control group, although this bias should have been minimal as all subjects were assessed by experienced physicians and were then independently allocated into the patient groups. More importantly, the 'gold standard' we used for final diagnoses in this study was based solely on the independent conclusions of experienced physicians. We lack longterm follow up, however, which would strengthen our findings by compensating for any diagnoses that were incorrect. On the other hand, there is a good evidence that a diagnosis of irritable bowel syndrome, once carefully made by a gastroenterologist, is unlikely to be altered with time..$^{1516}$

Other groups have utilised different approaches to diagnose irritable bowel syndrome by symptomatic criteria. Kruis and coworkers, for example, found that the presence of bowel irregularity, flatulence and abdominal pain separated significantly irritable bowel syndrome from patients with organic disease. Simple markers of organic disease, however, such as the haemoglobin and white cell count carried more weight than the symptoms." We found that the three symptom criteria devised by Kruis et al were present in $68 \%$ of all irritable bowel syndrome patients, $40 \%$ of organic gastrointestinal disease patients and in $6 \%$ of healthy subjects. This combination of symptoms, however, was not of significant discriminating value over and above the Manning criteria. Whatever criteria are used, disorders such as laxative abuse or lactose intolerance may produce symptoms that can be confused with irritable bowel syndrome. ${ }^{17}$ 
Moreover, $100 \%$ specificity would be impossible as irritable bowel syndrome symptoms are common in the general population ${ }^{1820}$ and in patients with organic disease, ${ }^{21}$ and the predictive value of any criteria will vary according to the prevalence of the disease in the population being assessed. Despite these problems, our findings indicate that the Manning criteria, if present, are of diagnostic value.

Whether the conclusions of this study apply to the general population is less certain. It is possible that those subjects in the community with irritable bowel syndrome who do not present for medical care have different symptomatology..$^{18-20}$ It is more likely that sociocultural factors rather than the type or severity of symptoms lead to differential health care seeking by irritable bowel syndrome sufferers, ${ }^{1922}$ suggesting that the criteria of Manning et al will also apply in the community.

In conclusion, symptom responses can lead to a positive diagnosis of irritable bowel syndrome and the six criteria of Manning et al are specific. Further studies are needed to determine if modification of these criteria can result in improved accuracy. Eventually, it may be possible to develop even better diagnostic criteria that will prevent unnecessary testing to rule out organic disease. At present, however, irritable bowel syndrome still remains a difficult positive diagnosis in some patients who present with atypical colonic symptoms.

Supported in part by Grant DK 34988 to the Mayo Digestive Diseases Center from the National Institutes of Health, United States Public Health Service.

1 Harvey FRD, Salih SY, Read AE. Organic and functional disorders in 2000 gastroenterology outpatients. Lancet 1983; i: $632-4$.

2 Manning AP, Thompson WG, Heaton KW, Morris AF. Towards positive diagnosis of the irritable bowel. Br Med $\dot{F}$ 1978; ii: $653-4$.
3 Thompson WG. The irritable bowel: one disease, or several, or none? In: Read NW, ed. Irritable bowel syndrome. London: Grune and Stratton, 1985: 3-16.

4 Talley NJ, Piper DW. The association between non-ulcer dyspepsia and other gastrointestinal disorders. Scand $\mathcal{F}$ Gastroenterol 1985; 20: 896-900.

5 Cook IJ, van Eeden A, Collins SM. Patients with irritable bowel have greater pain tolerance than normal subjects. Gastroenterology 1987; 93: 727-33.

6 Whitehead WE, Bosmajian L, Zonderman AB, Costa PT, Schuster MM. Symptoms of psychologic distress associated with irritable bowel syndrome. Comparison of community and medical clinic samples. Gastroenterologv 1988; 95: 70914.

7 Kellow JE, Phillips SF. Altered small bowel motility in irritable bowel syndrome is correlated with symptoms. Gastroenterology 1987; 92: 1885-93.

8 Heaton KW. Irritable bowel syndrome. In: Bouchier IAD, Allan RN, Hodgson HJF, Keighley MRB, eds. Textbook of gastroenterologv. London: Ballière Tindall, 1984: 867-75.

9 Thompson WG. Gastrointestinal symptoms in the irritable bowel compared with peptic ulcer and inflammatory bowel disease. Gut 1984; 25: 1089-92

10 Kapoor KK, Nigam P, Rastogi CK, Kumar A, Gupta AK. Clinical profile of irritable bowel syndrome. Ind $\mathcal{f}$ Gastroenterol 1985; 4: 15-6.

11 Kruis W, Thieme $\mathrm{CH}$, Weinzierl $\mathrm{M}$, et al. A diagnostic score for the irritable bowel syndrome. Its value in the exclusion of organic disease. Gastroenterology 1984;87: 1-7.

12 Talley NJ, Phillips SF Non-ulcer dyspepsia: potential causes and pathophysiology. Ann Intern Med 1988; 108: 865-79.

13 Talley NJ, Phillips SF, Melton LJ, Wiltgen C, Zinsmeister AR. A patient questionnaire to identify bowel disease. Ann Intern Med 1989; 111: 671-4.

14 Kramer MS, Feinstein AR. Clinical biostatistics. LIV. The biostatistics of concordance. Clin Pharmacol Ther 1981; 29: $111-23$.

15 Harvey RF, Mauad EC, Brown AM. Prognosis in the irritable bowel syndrome: A 5-year prospective study. Lancet 1987; i: 963-5.

16 Holmes KM, Salter RH. Irritable bowel svndrome - A safe diagnosis? Br Med F 1982; 285: 1533-4.

17 Drossman DA. Diagnosis of the irritable bowel syndrome. A simple solution? Gastroenterologv 1984; 87:224-5.

18 Thompson WG, Heaton KW. Functional bowel disorders in apparently healthy people. Gastroenterologv 1982; 83: 283-8. 9 Drossman DA, Sandler RS, McKee PC, Lonty AJ. Bowel patterns among subjects not seeking health care. Use of a questionnaire to identify a population with bowel dysfunction. Gastroenterology 1982; 82: 529-34.

20 Sandler RS, Drossman DA, Nathan HP, McKee DC. Sympcom complaints and health care seeking behaviour in subjects with bowel dysfunction. Gastroenterology 1984; 87 : $314-8$.

21 Isgar B, Harman M, Kaye MD, Whorwell PJ. Symptoms of irritable bowel syndrome in ulcerative colitis in remission. Gut 1983; 24: 190-2.

22 Welch GW, Hillman LC, Pomare EW. Psychoneurotic symptomatology in the irritable bowel syndrome: a study of reporters and non-reporters. Br Med F 1985; 281: 1382-4. 